\title{
Desdoblamiento de género como recurso pragmalingüistico en una "tradición discursiva profesional" de la prensa española de los siglos XVIII y XIX
}

\author{
JuLián Sáncha Vázquez \\ Universidad de Cádiz \\ Facultad de Filosofia y Letras \\ Avda. Gómez Ulla s/n \\ 11003 Cádiz (España) \\ SOBRE CRIADOS Y CRIADAS. \\ DESDOBLAMIENTO DE GÉNERO \\ COMO RECURSO PRAGMALIN- \\ GÜÍSTICO EN UNA "TRADICIÓN \\ DISCURSIVA PROFESIONAL" DE \\ LA PRENSA ESPAÑOLA DE LOS \\ SIGLOS XVIII Y XIX
}

RESUMEN: En este trabajo se ha estudiado el fenómeno del desdoblamiento de género como una "regla discursiva" en una serie de textos concretos dentro de la prensa de los siglos XVIII y xIx, la cual conformaría lo que aquí se ha denominado una "tradición discursiva profesional". Esta necesidad referencial de apelar a los dos sexos de los que escribian en dichos periódicos se estudiará a través de la lingüistica de corpus con el rastreo de distintos testimonios. El objetivo será, por tanto, el de estudiar la conciencia lingüística observable en dichos textos a través del uso implícito que los hablantes harian de una técnica pragmático-discursiva $u$ oral como la "antineutralización de género" en discursos históricos determinados.

PALABRAS CLAVE: pragmalingüistica histórica; tradiciones discursivas; género gramatical; desdoblamiento de género; género y sexo.

SUMARIO: 1 . Marco teórico del estudio: ¿tradiciones discursivas como espacios textuales para la designación óntica del sexo? 2. El desdoblamiento en la "TD profesional" de la prensa española. 3. Visión panorámica del fenómeno en la prensa decimonónica. 4. Conclusiones
GENDER SPLITTING AS A PRAGMATIC-DISCURSIVE TECHNIQUE IN A "PROFESSIONAL DISCURSIVE TRADITION" IN EIGHTEENTH- AND NINETEENTH-CENTURY SPANISH PRESS

ABSTRACT: In this article, I will study gender splitting resource as a "discursive rule" in texts from the eighteenth- and nineteenth-century press, specifically within what has been called a "professional discursive tradition". I will analyse the explicit reference to both sexes by those who wrote in these newspapers, thanks to corpus linguistics and the tracing of different testimonies. As a result, I aim to explore the linguistic awareness that can be observed in these texts, by studying the implicit usage of speakers. In doing so, I will pinpoint the way they materialise an oral or pragmatic, discursive technique as the gender antineutralisation in specific historical discourses.

KEYWORDS: historical pragmatics; discursive traditions; grammatical gender; gender splitting; gender and sex.

SUMMARY: 1 . Theoretical framework of the study: discursive traditions as textual spaces for the designation of sex? 2. Gender splitting in "professional discursive tradition" of the Spanish press. 3. Panoramic vision of the phenomenon in the nineteenth-century press. 4 . Conclusions

\begin{abstract}
DÉDOUBLEMENT DE GENRE COMME RESSOURCE PRAGMALINGUISTIQUE DANS UNE "TRADITION DISCURSIVE PROFESSIONNELLE, DE LA PRESSE ESPAGNOLE DES XVIIIE ET XIXE SIÈCLES
\end{abstract}

RÉSUMÉ: Dans cette étude, on s'est intéressé au phénomène de dédoublement du genre en tant que " règle discursive " dans une série de textes concrets issus de la presse des XVIIIe et XIXe siècles, celle-ci constituant ce que nous avons ici appelé une " tradition discursive professionnelle ".On étudiera cette nécessité référentielle de faire appel aux deux sexes chez ceux qui écrivaient dans ces journaux à travers la linguistique de corpus grâce au suivi de plusieurs témoignages. L'objectif sera par conséquent d'étudier la conscience linguistique observable dans ces textes à travers l'utilisation implicite que les locuteurs feraient d'une technique pragmatico-discursive ou orale telle que "l'antineutralisation du genre " dans des discours historiques donnés.

MOTS-CLÉS: pragmatique historique ; traditions discursives ; genre grammatical ; dédoublement du genre; genre et sexe.

SOMMAIRE: 1 . Cadre théorique de l'étude: les traditions discursives comme espaces textuels pour la désignation ontique du sexe? 2. Le dédoublement du genre dans le "TD professionnel" de la presse espagnole. 3. Vision panoramique du phénomène dans la presse du XIXe siècle. 4 . Conclusions 


\title{
Desdoblamiento de género como recurso pragmalingüistico en una "tradición discursiva profesional" de la prensa española de los siglos XVIII y XIX ${ }^{1}$
}

\author{
Julián SANCha VÁZQUEZ
}

\section{Marco teórico del estudio: ¿tRadiciones discursivas como espacios TEXTUALES PARA LA DESIGNACIÓN ÓNTICA DEL SEXO?}

\subsection{Pragmalingüística histórica y tradiciones discursivas}

Lo "sexual" en lingüística presupone una trampa mortal, a saber, que incluso ahí donde pudiéramos encontrar rasgos de una realidad sexuada plasmados en las lenguas, estos no serían más que meras representaciones simbólicas. A su vez, si entendemos la lengua en su conjunto como un modelo de representación cuando atendemos específicamente a la dimensión "género" gramatical, no se podría decir que esta determine una relación causal entre lengua y realidad extralingüística, es decir, que dos dimensiones como el género gramatical masculino y el género gramatical femenino no se podrian explicar, respectivamente, como correlatos de los rasgos 'macho' y 'hembra' de la realidad designada (Rivas Zancarrón, 2018a; Escandell-Vidal, 2018, 2020; Sancha Vázquez, 2020a y b). Sin embargo, a veces la lengua española sí responde dimensionalmente a la designación lingüístico-óntica del sexo, de lo que los hablantes son capaces desde hace mucho tiempo a través de múltiples estrategias ${ }^{2}$.

Estas estrategias pudieron ser llevadas a cabo en la tradición discursiva que exploraremos en este texto, de un lado, desde el nivel morfológico en fórmulas como "criados, y criadas", así como, de otro lado, desde el nivel sintáctico, con perífrasis del tipo "los trabajadores de uno y otro sexo". Ambas posibilidades servirian para matizar el concepto "bimembración" o "desdoblamiento de género" ${ }^{3}$. Aceptada esta

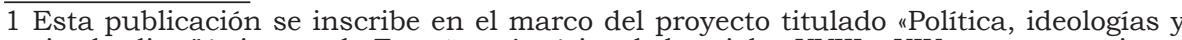
actitudes lingüísticas en la España y América de los siglos XVIII y XIX: un acercamiento desde los textos periodísticos y gramaticales" (ref. PID2020-115226GB-100), subvencionado por el Ministerio de Ciencia e Innovación.

2 Lo que ha llevado a considerar el género gramatical como un campo de batalla glotopolítico en los estudios enmarcados en la denominada crítica feminista del lenguaje (cf. Lledó y Cunill, 2012; Llamas Sáiz, 2015; Bengoechea, 2015; Muntané, 2018; Del Valle, 2018 y Castillo Sánchez y Mayo, 2019). Un estudio más pormenorizado de las diferentes ideologías en el presente sobre el género gramatical, tanto la hegemónica como las alternativas, ha sido ya presentado en Sancha Vázquez (2020b).

3 En este sentido, el desdoblamiento no se trataría solo de un simple fenómeno de bimembración morfológica (todos y todas), sino que podría estudiarse como una "antineutralización", término que se explicará más adelante $(\& 1.2)$. Este podría darse tanto desde el plano morfológico como desde el plano sintáctico a la hora de antineutralizar rasgos semánticos de lo 'macho' y lo 'hembra', ya fuese en morfemas o en perifrasis contextuales. Por ejemplo, es un fenómeno muy común "antineutralizar" los epicenos, dada su designación óntico-sexual cero: "las personas de uno y de otro sexo", donde estos dos rasgos semánticos estarian neutralizados in absentia dentro de la propia palabra. De existir la posibilidad (potencial desde el punto de vista del sistema, y no desde nuestra "norma sincrónica") de antineutralizar un epiceno en el nivel morfológico, podría decirse *persono, pero cuando esto pareciera toda- 
premisa por la que la lengua española se comportaría como un organismo mutante, la cual a veces sería potencialmente designadora del sexo a través de estructuras gramaticales, y otras veces no lo sería, en este texto cabe plantearse una primera pregunta: ¿cómo podríamos analizar, a través de la pragmalingüistica histórica, un fenómeno como el desdoblamiento de género para la designación del sexo en textos concretos y, sobre todo, de qué manera podríamos clasificarlo?

Como veremos, esta problemática relación entre la gramática y el sexo podría engarzarse con el concepto de "tradición discursiva" (TD) introducido por la filología alemana heredera de la teoria del lenguaje de Coseriu (Loureda Lamas, 2006; Koch, 2008; Koch y Oesterreicher, 2001, 2007 y Kabatek, 2018). Si bien el concepto se ha aplicado generalmente a la explicación del cambio lingüístico en diacronía (Kabatek, 2008), aquí, por el contrario, vamos a aplicar dicho concepto para lo que se ha llamado una "pragmalingüística de las tradiciones discursivas de inspiración coseriana" (Schrott, 2017: 37), esto es, vamos a estudiar un fenómeno que no tiene por qué presentar ni cambio ni continuidad, sino que se trataría simplemente de un recurso del hablar individual e histórico que acontecía en interacciones concretas dentro de un conjunto de textos históricos ${ }^{4}$.

Además, "la investigación de las tradiciones discursivas se distingue por un pensamiento lingüístico orientado hacia la interacción verbal y sus saberes, ya que el hablar como actividad (energeia) genera tradiciones y costumbres, y de este modo, crea cultura" (Coseriu, 1992). Sobre esta interacción verbal con una historia tras de sí es sobre la que orbitarán las hipótesis de esta investigación a la hora de cribar diferentes testimonios.

Por tanto, en este trabajo nos proponemos verificar cómo dichos textos, debido a sus diferentes características contextuales, parecían propulsar un mismo fenómeno - el desdoblamiento de género-, recurso pragmático-discursivo que tendría que ver con la necesidad referencial que presentaron históricamente los hablantes de la lengua española cuando necesitaban apelar a personas de ambos sexos, hecho que parecía, a su vez, motivado por el tipo de tradición discursiva en el que estos se insertaban 5 .

vía imposible, la manera de hacerlo debería pasar por lo contextual. Al hecho de desdoblar ambos sexos a través de estructuras gramaticales, independientemente de la característica que presente un sustantivo o un morfema concreto, lo llamaremos "desdoblamiento de género" de aquí en adelante dado que ambas posibilidades se vertebran con un mismo fin. 4 Esto es así puesto que "como saber histórico, las tradiciones discursivas pueden ser transmitidas continua o discontinuamente. Un saber discursivo-tradicional determinado puede perderse y luego volver a ser reactivado. En este sentido, las tradiciones discursivas son potencialmente transhistóricas: no están ligadas a un desarrollo histórico continuo, sino que pueden manifestarse en la historia con interrupciones" (Schrott, 2017: 29). Dado que este análisis de herramientas pragmático-discursivas en el hablar concreto tiene que ver con el concepto de "interacción" y las máximas del hablar (Moreno Fernández, 2012:109), en trabajos anteriores (Sancha Vázquez, en prensa) hemos analizado el desdoblamiento bajo el prisma de la sociolingüística cognitiva en corpus históricos, aunque fuesen escasos los trabajos diacrónicos amparados bajo los presupuestos teóricos de dicha rama de conocimiento. 5 Como bien explica Schrott (2017: 27): "La diversidad de los fenómenos hace que el término de las tradiciones discursivas parezca un término paraguas, sin embargo, su gran envergadura no debe ocultar que se trata de un paraguas sólido. El vínculo unificador de las tradiciones discursivas es que fijan el hablar en situaciones concretas de comunicación". 


\title{
1. 2. Antecedentes y ESTAdo de LA CUESTIÓN SOBRE LA BIMEMBRACión DE GÉNERO
}

El desdoblamiento de género ha sido tratado también en el ámbito de la Edad Media por Almeida Cabrejas (2012, 2016) y las investigadoras Lobo Puga, Martín Aizpuru y Sánchez Romo (2015), en lo tocante a textos jurídicos en el castellano antiguo, siendo estas últimas quienes han afirmado lo que sigue:

\begin{abstract}
Hemos comprobado que las estructuras de desdoblamiento de género halladas en el corpus cancilleresco de Miranda no son casos aislados sino que podrian formar parte de una tradición escrituraria, en la medida en que las estructuras bimembres están presentes también en otros corpus jurídicos y en diversos tipos de obras literarias o científicas desde, al menos, el siglo X. Además, su uso en la documentación legal no es ornamental sino que sirve para concretar las personas a las que se refiere el acto jurídico.
\end{abstract}

Hay que destacar que esta "tradición escrituraria" (la tradición discursiva de lo jurídico) se guía por el criterio de evitar cualquier tipo de ambigüedad, sobre todo en lo referente a las personas sobre las que se legisla y se prescribe. Por esto, desde muy antiguo se pueden observar numerosos casos como "omne o mugier", "padre y madre", "moro o mora" 6 .

Asimismo, en la tradición discursiva de los textos religiosos, suelen encontrarse referencias al sexo de los mencionados y apelados, como ocurre, por ejemplo, en algunas suras del Corán, ya que el árabe para estos casos dispone del mismo recurso discursivo que la lengua españo$1 a^{7}$. La línea de este trabajo va a perseguir, en cambio, orientar el análisis de estas estrategias en otra tradición discursiva aún no explorada, así como su abordaje se realizará en un espacio de tiempo más cercano al

Por lo que, independientemente de los diversos problemas terminológicos a los que ha conducido dicho "fuzzy concept" (ibid.), al haber sido empleado de muy diferentes maneras (Koch, 1997: 45, apud Schrott, 2017), es en dicho hablar histórico donde insertaremos la técnica pragmático-discursiva del desdoblamiento que estudiaremos en este trabajo. Para entender la compleja e inagotable discusión sobre el concepto, véase López Serena (2021). Así, el concepto de TD puede relacionarse con el "saber expresivo" dentro de la teoría coseriana de la competencia comunicativa del hablante y dentro del plano individual del habla, lo que nos conduce a su vez al "saber discursivo-tradicional", ya que "una característica fundamental de las tradiciones discursivas es su omnipresencia en el hablar. Es decir que todo hablar no está sujeto solamente a las reglas generales y universales del hablar, sino que también es preconfigurado por tradiciones discursivas como moldes para toda interacción verbal" (Schrott, 2017: 28). En este sentido, las diferentes estrategias discursivas de la lengua española podrían tener también mucho que ver con la tradición donde el hablante se inscribe, consciente o inconscientemente, y para las que estará predispuesto a hablar - o escribir- de uno u otro modo.

6 Como ha investigado Almeida Cabrejas (2016), las propias leyes alfonsies aclaraban el uso del "masculino no marcado" como referente a la totalidad, o sea, para referirse a ellos y a ellas, sin olvidar a la mujer de las posibles sentencias o dictámenes: "Del entendimento \& del significamiento de otras palabras escuras. Usamos a poner en las leyes deste nuestro libro diziendo tal onbre que tal cosa fiziere aya tal pena y entendemos [que] aquella palabra quel defendimiento pertenesçe tan bien a la muger commo al varon maguer que no fagamos y miente en aquellas cosas señaladas que les otorgan las leyes deste nuestro libro (Partida VII, título XXXIII, ley VI)".

7 Por ejemplo, los versos de la sura número 35 podrían corresponder a una traducción como la que sigue: "Alá ha preparado perdón y magnífica recompensa para los musulmanes y las musulmanas, los creyentes y las creyentes, los devotos y las devotas, los sinceros y las sinceras, los pacientes y las pacientes, los humildes y las humildes, los que y las que dan limosna, los que y las que ayunan, los castos y las castas, los que y las que recuerdan mucho a Alá". 
de nuestros dias. Esto podría demostrar, a su vez, la vigencia a lo largo del tiempo de un artilugio discursivo como el desdoblamiento de género cuando el hablante tuviese dicha necesidad referencial, propiciada esta, en muchos casos, por el tipo de texto al que se adscribía el mismo ${ }^{8}$.

En este sentido, atendiendo a lo que realmente representaría una "tradición discursiva", Grijelmo (2019: 34) vinculaba este fenómeno con el concepto de "lengua cultivada":

\begin{abstract}
Entendemos que esa lengua cultivada se usa habitualmente en público y requiere de un esfuerzo a cargo de quien habla o escribe. Algo que no ocurre en las conversaciones entre amigos, compañeros o familiares. por eso mismo, quienes en el lenguaje político dicen "españoles y españolas", "argentinos y argentinas", "chilenos y chilenas" o "amigos y amigas" suelen apearse de esas exigencias cuando salen del escenario y se refieren a los "invitados" que llegarán a cenar o a la reunión de su comunidad de "vecinos".

Incluso abandonan los dobletes en sus intervenciones públicas cuando al hablar reducen su capacidad de concentración, o si han avanzado en su exposición y perciben como tediosas esas construcciones.
\end{abstract}

Además, cabría preguntarse también si esta estrategia de dicha "lengua cultivada" formaría parte de diferentes tradiciones discursivas o si en realidad, podría conformar en sí misma una tradición discursiva. Desde un punto de vista teórico, en el conocido trabajo de Koch (2008), este autor decia que las tradiciones discursivas pertenecen "al nivel histórico pero se distinguen claramente de las lenguas históricas particulares", donde todos los elementos siguientes podrian conformar una TD: "editorial, novela, small talk, chiste; estilo llano, manierismo; diferentes actos lingüísticos como bautizar, prometer, etc.". También Schrott (2017: 28) decía al respecto que:

De esta forma, rutinas comunicativas tales como la formulación de una
petición o un género textual se pueden identificar como saber discursi-
vo-tradicional porque sirven como guía a los interlocutores al aplicar es-
tructuras lingüisticas de modo que se cumpla adecuadamente una ta-
rea comunicativa, ya sea la apertura de una conversación o la creación de
una obra literaria. Además, las rutinas comunicativas y los géneros tex-
tuales tienen en común que son independientes de la lengua particular.

En este sentido, ¿qué entendemos por "tradición discursiva" aquí? Se constata una duplicidad dentro del "nivel histórico" de las lenguas de Coseriu, la cual ya ha sido ampliamente criticada, donde se deberian insertar las tradiciones discursivas como entes independientes de las lenguas particulares, es decir, como modos especificos de hablar en los textos a través de estas lenguas por una serie de comunidades de habla ( $c f$. Kabatek, 2000; Fernando Lara, 2004: 71-87). Es así como llega a hablar Koch (2008: 55) de "reglas idiomáticas" para las lenguas y "reglas discursivas" para las tradiciones discursivas. Dicho de esta manera, cuando se habla de la "anormatividad" del desdoblamiento como estrategia discursiva con el fin de criticarlo, no se estaría reali-

8 Por esta misma razón, el desdoblamiento de género actualmente es también una herramienta utilizada en el discurso político (que podría considerarse en sí mismo una tradición textual con entidad propia), incluso cuando no se trata de una verdadera necesidad referencial, lo que muestra también la actitud, así como un marco de ideologias lingüísticas del hablante ante el fenómeno (Grijelmo, 2019: 33-43; Sancha Vázquez, 2020b). 
zando una descripción pertinente del fenómeno, pues este tendría una naturaleza puramente discursiva cuando un hablante lo ejecuta en un acto verbal concreto y, en este sentido, el discurso no tendría por qué necesariamente tender a la economía. Asimismo, este acto discursivo podría definirse dentro de esas "reglas discursivas" en diferentes tradiciones textuales sin que esto haya promovido cambio en el nivel idiomático de la lengua; o, por el contrario, podría también definirse como una tradición discursiva en sí misma. O sea, que se trataría de un problema de la lingüística del texto dentro de un hablar histórico (el saber "discursivo-tradicional"), el cual remite igualmente al "saber expresivo" coseriano en el nivel individual del habla y no, por el contrario, al nivel idiomático de la lengua ${ }^{9}$. Tanto es así que podría estudiarse un efecto expresivo a lo largo del tiempo dentro de una tradición sin que necesitemos demostrar un cambio lingüístico, para lo que tal vez el concepto de las TD podría tener también utilidad, y de lo que se pretende asimismo dar testimonio en este trabajo.

Para analizar la utilidad del concepto "tradición discursiva" a la hora de entrar en contacto con el desdoblamiento de género, deberíamos atender a los conceptos que en pragmalingüística histórica se han descrito como "fijación definitoria", "grado de especificación cultural" e "integración" (Schrott, 2017: 31-32). En primer lugar, la "fijación definitoria" habla, a su vez, de "conceptos de uso cotidiano" (rutinas comunicativas, estilos de interacción, etc.) donde el hablante sería inconsciente de esta tradicionalidad, y, por otro lado, de "fijación definitoria" en el sentido de que el hablante ahora sí tendría conciencia de la tradicionalidad (el editorial, el reportaje, géneros textuales literarios, etc.). En este sentido, el desdoblamiento podría ser estudiado como una TD en sí misma al tratarse de un "concepto de uso cotidiano" de cuya tradicionalidad el hablante no tiene conciencia, dado que este simplemente lo utiliza y lo ha utilizado a través del tiempo. O bien, al mismo tiempo, podría reconocerse como una regla dentro de otras TD superiores para las que el hablante si tendría conciencia de su tradicionalidad.

Además, otro segundo requisito entiende que "cuanto más específica es una tradición discursiva, más depende de los conocimientos previos culturales de los que solo dispone un grupo de hablantes comparativamente pequeño" (ibid.: 32), y, al contrario, que si se tratase de unas TD no tan específicas, estas "son dominadas por un grupo mayor de hablantes, están arraigadas en el uso cotidiano de la lengua, a menudo son de carácter general y pueden, en este caso, estar vinculadas a las reglas universales del hablar", como creemos que sucedería con una técnica ampliamente utilizada a lo largo del tiempo como el desdoblamiento ${ }^{10}$. Por último, el concepto de "integración"

9 Cf. Coseriu (1992: 87-91).

10 De esta manera, dice Schrott (2017: 35): "como todo hablar tiene lugar en el marco determinado por las reglas universales-generales, las tradiciones discursivas son las modelaciones históricas y culturales de estas reglas generales [...]. Un principio general del hablar especialmente influyente es el principio de cooperación de Grice, en el que se basan las tradiciones discursivas", lo que curiosamente también es analizado por la sociolingüística cognitiva; de ahí que en otros trabajos tendimos a aunar esta disciplina con este fenómeno incluso en el nivel histórico ( $c f$. Sancha Vázquez, en prensa). 
habla de "tradiciones aisladas" que valen por sí mismas frente a otras que formarian "parte de un todo mayor". Por ejemplo, las "formas de saludo [...] pueden cumplir su función sin otro apoyo y constituyen una técnica cultural que funciona de forma autónoma" (ibid.), lo que podría decirse también del desdoblamiento, y, a su vez, también podría afirmarse que pueden formar parte de una unidad más amplia (tanto los saludos como el desdoblamiento se darian, a su vez, en tipos de textos concretos - conferencias, género textuales determinados, etc.- $)^{11}$. Además de esto, el desdoblamiento formaría parte de otras TD superiores como estrategia del "hablar universal" que se reproduce igualmente en el "hablar tradicional", ya que podría considerarse como una estrategia destinada a la violación de algunas de las máximas del "principio de cooperación" de Grice, la cual rompería concretamente la máxima de cantidad, y ya "que el principio de cooperación guia el hablar en los contextos comunicativos, esta conexión aporta una perspectiva pragmalingüística al saber discursivo-tradicional [...]. Así, una tradición discursiva puede cumplir una máxima, pero igualmente puede torcerla (aparentemente) o violarla" (Schrott, 2017: 35). Esta argumentación, la que explicaria el desdoblamiento de género, en primer lugar, como su propia tradición discursiva y, en segundo lugar, como una técnica de tradiciones discursivas superiores, podría poner en jaque la crítica ejercida por algunos autores que han entendido el desdoblamiento de género como una atrocidad contra el sistema lingüístico del español, el cual pareciera estar en peligro cuando alguien acudiera a su uso ${ }^{12}$

En otro orden de cosas, dentro de una TD superior donde este fenómeno también tuviera lugar, el desdoblamiento podria hallarse dentro de un conjunto de textos que aquí hemos agrupado en la denominada "TD profesional». Tal y como se ha definido una TD (Kabatek apud Loureda Lamas, 2006: 136), esta podría hallarse en textos, los cuales, una vez agrupados, se definieran con base en unos "rasgos esenciales" que el hablante podría conocer "intuitivamente", y donde uno de estos "rasgos" sería la técnica —o la TD- del desdoblamiento y la bimembración de género. Además, la mención a distintas profesiones o cargos sociales y aquella necesidad discursivo-referencial de mencionar sujetos en estructuras

11 Pensamos que la hipótesis aquí propuesta debería estudiarse con cuidado y tenerse en cuenta para posteriores investigaciones, dado que hasta ahora no hay literatura al respecto, es decir, el hecho de que el desdoblamiento de género pueda ser en sí mismo una tradición discursiva aislada y, asimismo, formar parte como técnica integral de tradiciones discursivas mayores.

12 Hablamos de autores como Grijelmo (2019: 57) que siguen la misma línea de pensamiento crítico que la Real Academia Española (Bosque, 2012), pues el periodista reconoce que "la duplicación obsesiva puede desatar un efecto opuesto a lo pretendido por sus impulsores. El exceso en los dobletes tiende a resultar contraproducente por agotador y artificial, y se corre el riesgo de que el receptor de los mensajes desconecte de su contenido". Sin embargo, habria que explicar que estos desdoblamientos no se producen en cualquier texto, sino en algunos determinados y por razones pragmáticas (si bien es cierto que en determinados textos políticos actuales se está abusando de este recurso y por unas razones equivocadas: ibid.: 33-112), como también ha investigado de manera abundante el profesor Roca (2005a, 2005b, 2009, 2012). En el marco de este trabajo, el desdoblamiento estudiado tendría poco que ver con el discurso político $\mathrm{y}$, como se ha visto, más con un fenómeno permitido por el sistema de la lengua española desde sus orígenes y que no tiene por qué repetirse todo el tiempo, sino que tendría sentido en una "interacción" concreta y determinada. 
bimembres podria darse en escritos de diferente tipologia que aunasen este mismo rasgo. De aceptarse entonces que el tipo de texto presente en los testimonios aquí recogidos de la prensa aúna ese conjunto de rasgos que lo haria particular frente a otros en textos diversos (por ejemplo, otros de tipo religioso o estadístico —donde también podria darse el desdoblamiento por motivos similares pero con otras características-) ${ }^{13}$, dentro de la prensa podría hablarse de otra "tradición discursiva" específica.

En esta, el tipo de texto basado en anuncios, y, en general, aquel donde se aludiese a profesiones y cargos sociales concretos, compondría ese espacio textual de interacción para el escribiente que resultaría ideal para realizar constantes antineutralizaciones a través del desdoblamiento ${ }^{14}$. Es también por esta razón por la que pensamos que aquí sería mejor hablar de "tradición discursiva" y no simplemente de "género discursivo" o "tipo de texto", etcétera, ya que una misma tradición podría englobar diferentes "géneros textuales", como se verá, pues varios de estos podrian responder a unos mismos rasgos, entre los que podría recogerse (como se pretende demostrar) un recurso oral y pragmático-discursivo como es el desdoblamiento de género.

Por último, el desdoblamiento de género se podría dar en la presencia de estructuras bimembres, esto es, donde dos elementos que viven "sincretizados" en una forma, en un momento del discurso determinado se separaban en dos formas para hacer explícito un contexto extralingüístico que importaba (en este caso, la realidad sexuada de un ente designado a través de un signo - ya fuese este un morfema o una palabra-) ${ }^{15}$.

Asimismo, como se ha demostrado en otra TD, la denominada "tradición discursiva escolar" donde el desdoblamiento de niños y niñas, maestros y maestras, etc., acontecía con absoluta normalidad en el discurrir de los textos de aquella época conformando su propia tradición, donde se pudo describir esta misma "regla discursiva" que la propia realidad histórica propiciaba (Sancha Vázquez, en prensa), razón también por la

13 Cf. Sancha Vázquez (2019: 386-432).

14 Para ampliar información sobre el concepto estructural de "antineutralización" tan poco estudiado por la filología, sobre todo en relación con problemas designativos del género, véase Sancha Vázquez (2020a: 99-154).

15 De modo que hablaremos aquí de una "antineutralización sociolingüística", puesto que esta estaría motivada por una actitud del hablante, quien, en el momento de la interacción, precisaba designar los dos sexos, los cuales, dentro de la dimensión "género no marcado" (por ejemplo, en el morfema -o de una voz como criados), estarian ocultos puesto que sirve para la "generalidad" de la forma no marcada. De seguir esta línea de pensamiento, esta ocultación de los rasgos 'macho' y 'hembra' en la -o que cumple como función no marcada del género podría considerarse un "sincretismo de género" puesto que estos dos rasgos se hallarian neutralizados en este paradigma del sistema morfológico. Por esta razón, en el momento del habla se necesitaria "antineutralizar" esta -o con el recurso de ampliar el enunciado y añadir criados y criadas, por ejemplo, lo que desharía la ambigüedad manifestada en la neutralización de aquellos rasgos semánticos ( $c f$. Sancha Vázquez, 2020b: 99-154). Hablar de "antineutralización" ha resultado problemático desde el punto de vista del género, sin embargo ya lo hizo Coseriu (1969) en un trabajo al hablar de los lobos y las lobas en la lengua francesa. Además, este concepto engloba tanto el «desdoblamiento" morfológico (criados y criadas), o sea, el que se realiza utilizando el mismo término con diferente morfema flexivo, así como el sintáctico, el que se hace a través de requiebros contextuales como "las personas tanto del sexo masculino como del sexo femenino"..., lo que, aunque en diferentes niveles lingüísticos, consideramos la misma estrategia antineutralizadora para resaltar el sexo a través de estructuras gramaticales ( $c f$. para mayor profundización en Sancha Vázquez, 2020a: "la injerencia del sexo en el lenguaje»). 
que hemos preferido optar por el estudio del desdoblamiento como una tradición discursiva que forma parte a su vez de tradiciones discursivas mayores, la que aquí, en este texto, hemos denominado "TD profesional».

\section{El desdoblamiento en LA "TD PROFEsional" DE LA PRENSA ESPAÑola}

La relación de textos aquí presente es, por tanto, tan solo una pequeña parte de un corpus mayor que contó con una cantidad cercana a los 1000 testimonios dentro del cotejo de un total de 256 periódicos analizados, pertenecientes a ambos siglos (ss. XVIII y XIX) y a ambas orillas del Atlántico, o sea, tanto en la prensa española como en publicaciones periódicas de Latinoamérica ( $c f$. Sancha Vázquez, 2019). En aquel trabajo se analizaron actitudes explícitas e implícitas a través de muy distintos testimonios, donde también se exploraron, entre otras cuestiones relativas al género gramatical, diferentes tradiciones discursivas donde también se encontraba la "TD profesional" a la hora de abordar la técnica del desdoblamiento de género ${ }^{16}$.

Dicho esto, vamos a analizar el conjunto de textos seleccionados con el fin de señalar este fenómeno pragmático-discursivo en la historia del español y dentro de una TD concreta. Comencemos advirtiendo el uso del desdoblamiento de género y su motivación semántica respecto de las profesiones en un caso como el del testimonio (1). En este caso particular se trata del primer diario profesional impreso en España, el Diario noticioso, curioso-erudito, y comercial, público, y económico, iniciado por uno de los periodistas más estudiados de la época, Francisco Mariano Nifo, quien, como se sabe, fue uno de los pioneros en acoger a la "opinión pública" en su medio a través de cartas y demandas de empleo, etcétera ${ }^{17}$. El propósito de enfocarnos en este hecho tiene que ver también con que hablamos de un medio incipiente que destacaba por su alto coste en imprenta y la necesidad, por tanto, de ahorrar o de usar un lenguaje cuanto menos comedido. Sorprende, tratándose en este caso de uno de los primeros diarios profesionales donde podian hallarse textos de este tipo, la constante de una "regla discursiva" como el desdoblamiento. El surgimiento de la prensa, nueva fuente de conocimiento para el «interés del público», nacía precisamente en condiciones especiales, pues la extensión del texto estaba condicionada por el espacio y la tinta, o sea, por motivos económicos. Pero incluso con estos condicionantes que invitaban a la economía lingüística en el siglo xviI, un autor (o varios) desdoblaba indiscriminadamente el género gramatical como proyección del sexo

16 Esta semilla creció dentro del proyecto de investigación Corpus diacrónico para el estudio de las actitudes lingüisticas en América y España en los siglos XVIII y XIX (FFI2016-76874-P), concedido por el Ministerio de Economía y Competitividad del Gobierno de España, donde se defendió un trabajo en el que se realizó un cotejo mayor para la construcción de un corpus. Dada la necesidad de mostrar ejemplos prácticos en este trabajo, debe precisarse que se tratará de una investigación de lingüística con corpus (y no así de corpus), pues con los testimonios elegidos en esta investigación no se ha pretendido más que la agrupación de una muestra representativa de lo que ocurriría a menudo en este tipo de textos concretos, que a su vez podrían conformar en última instancia una tradición discursiva.

17 Cf. Enciso Recio (1956). 
de los designados, en este caso, por ejemplo, para referirse al sexo de los criados o criadas. Posiblemente, su actitud frente a este desdoblamiento era la de no "excluir" ningún sexo al promocionar la oferta, incluso si la forma neutral criado pudiera designar ambos sexos (función no marcada del género). Esto ocurría, asimismo, porque las funciones de unos y de otras eran distintas socialmente, por lo que hacia falta seleccionar personas tanto de un sexo como del otro, es decir, había en la conciencia de quien hablaba una "necesidad referencial" que promovía dicha interacción verbal en el texto o discurso seleccionado. También podría destacarse el orden en el que se usaban dichas estructuras bimembres, dado que la cuestión del "foco" sería asimismo un recurso discursivo del habla. Dicho de otro modo, volviamos a encontrar marcas que señalarian "oralidad" en este tipo de fenómenos y de textos (\& 1. 2.) $)^{18}$. Generalmente, como se verá, el autor solia referirse primero a las señoras y criadas, tal vez debido a alguna cuestión de foco que la importancia de aquellas labores (ejercidas solo por ellas) precisaba. En el testimonio siguiente se repite esta orden, si bien al final en la última frase utiliza de manera "neutral" la forma criados, para desdoblarlo de nuevo en ellos y ellas:

(1) Punto septimo. Las señoras, Señores, Amas, ò Amos, de qualquier condicion que sean, y necessiten Criadas, ò Criados para qualquiera fuente de servicio domestico, pueden encontrar prontamente, y à satisfaccion suya quien les sirva, poniendo en noticia del Público las circunstancias de la Criada, ò Criado, que desean; y esto sin mas molestia, ni engorro, que el ningun trabajo de hacer una esquelita, en la que se remitan à la Imprenta del DIARIO las señas, y contraseñas de sus casas, para que vayan à vista los Criados, ò Criadas, que necesiten.

(Diario noticioso, curioso-erudito, 01/2/1758, p. 17)

A continuación, en (2) se encontró también un adjetivo desdoblado en el enunciado "entre tantos, y tantas", si bien finalmente, al referirse a la pluralidad, se refiere solo a "sus Amos", lo que ocurre cuando no resulta cómodo desdoblar todos los nombres y adjetivos en un mismo texto, como de hecho podría regir una regla tipológica en la búsqueda de una determinada cohesión textual, lo que han criticado algunos autores reacios a este fenómeno, concretamente en relación más a una exacerbación de este en el discurso político de la actualidad (\& 1 . 2.). Sin embargo, así funciona el nivel del habla —el discurso en la interacción también escrita-, pues importan fenómenos concretos por encima de una aparente cohesión, ya que este tipo de antineutraliza-

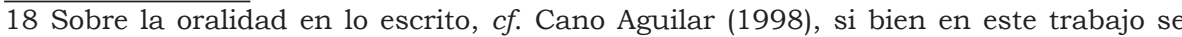
estaría definiendo una nueva herramienta como "marca de oralidad", en este caso el desdoblamiento en base a lo hasta aquí expuesto. 
ciones acontecen por un motivo pragmático determinado ${ }^{19}$. Asimismo, véase cómo cuando se habla de "algunos pobres Muchachos" a continuación se utiliza el género marcado para el sexo 'hembra', pues este cumple perfectamente con dichas funciones "femeninas" como "Costureras, y Aplanchadoras" y "algunas bien intencionadas Mugeres patricias, ó estrangeras, que se dedican voluntariamente à enseñar niñas à coser, y à otros labores, proprios del sexo delicado". Igualmente, "sus Amos" no se desdobla siempre:

(2) Reflexion. Las amas, y Amos con el espressado socorro adquirirán, sin la enfadosa diligencia de importunar à sus conocimientos los Criados, y Criadas que necesiten, y tan à su satisfaccion, como que tendràn, entre tantos, y tantas que havrà cada dia en el DIARIO, bastantes en que escoger. Este repetido aviso, respecto à este particular de Criadas, y Criados, serà en su modo un freno politico, que contendrà, en los limites de la razon, à los sirvientes; porque no es dudable, que viendo leer à sus Amos el DIARIO COMERCIAL-ECONÓMICO, se temeràn, si no cumplen con su obligacion, ser despedidos, pues tendràn sus Amas, como en las manos de su arbitrio, la facilidad de mejorar su assistencia: si ellos, por desatentos con su fortuna, la posible desgracia de exponerse à mas fatigosa servidumbre, ò acaso, à tributarle quexas, y sentimientos amargos al hambre. Punto octavo. Las Criadas, y Criados de todas condiciones, que se hallan sin conveniencia, ò acomodo, pueden hacer menos durable la fatalidad que sufren quando no sirven, dando parte al Pùblico de sus circunstancias, $\mathrm{y}$ las habilidades que tienen, $\mathrm{y}$ en què grado de servidumbre quieren colocarle, (escusando poner su nombre en la Esquela, por no ser del caso, y evitar qualquiera inconveniente) dando señas, y contraseñas ciertas, y seguras de la calle, y casa en que residen; pues parece cierto, que en un Pueblo tan numeroso, y dilatado como Madrid, no pueden (mediando este socorro) estar mucho tiempo desacomodados; ademàs, que muchas veces, y en particular algunos pobres Muchachos andan vagando sin acomodo, ni conveniencia, porque se ignora para què son buenos, y à que se inclinan.Asimismo son de este punto las Costureras, y Aplanchadoras de habilidad sobresaliente, y pueden tambien dar parte al Pùblico por una Esquela, del mismo modo que Criados, ò Criadas, para facilitarse por este seguro medio el alivio, que desean de tener que trabajar, para ganar honestamente la vida. Algunas bien intencionadas Mugeres patricias, ó estrangeras, que se dedican voluntariamente à enseñar niñas à coser, y à otros labores, proprios del sexo delicado, con la Esquela propuesta pueden saber à todos su deseo racional, y piadoso, y lograr mas facilmente que las niñas sean educadas, con utilidad suya, y aun de sus Padres.

(Diario noticioso, curioso-erudito, 01/2/1758, pp. 17-18)

19 En cualquier caso, ya que, como se está viendo en este trabajo, el fenómeno del desdoblamiento es resultado más bien de una "comunicación que opera con significados emergentes" (Moreno Fernández, 2012: 109), habría que justificar tal vez de una forma más detallada por qué estos usos lingüísticos concretos irian contra algún tipo de regla "tipológica" o de cohesión textual. El uso concreto y determinado de este fenómeno en según qué tradiciones discursivas, tal y como se ha intentado demostrar en este artículo, no correspondería a un patrón determinado de conducta que deba perseguirse siempre, sino, al contrario, a un uso discursivo único que se justifica en la propia interacción, al entenderse este como un fenómeno de "habla" individual y no así dentro de la totalidad del texto como una continuidad. En este sentido, esta crítica al desdoblamiento del género no tendría la misma razón de ser que una regla tipográfica que se usara de manera discontinua en un texto, lo que sí estaría faltando a la lógica que cohesionaria un texto completo (por ejemplo, el uso de la letra cursiva para una función y, en el mismo texto seguidamente, para otra). 
Como ya se ha explicado, el fenómeno de la bimembración también podrá ser sintáctico, como ocurría en (3): "las personas de uno, y otro sexo", lo que servía como clara antineutralización perifrástica para sonsacar el sexo que el epiceno persona escondía, dado que dichas estructuras gramaticales en la lengua española como lo son los sustantivos de género epiceno no designan sexo alguno ( $c f$. Sancha Vázquez, 2020: 130-138). Lo mismo ocurría en el sintagma "Criados, ò Criadas", pero en este caso con el desdoblamiento operado sobre los morfemas flexivos -o y -a. A su vez, la voz padres, por ejemplo, no se desdoblaba, donde permanecería intacto su sincretismo de género en la voz padre, la cual agrupa al mismo tiempo la oposición de los rasgos semánticos 'macho'/'hembra' de la oposición de heterónimos padre/madre. Además, en la reflexión que seguía a esas líneas donde denunciaba la prostitución a la que era destinada "esta especie de gentes", el autor desdoblaba en unos casos sí y en otros no. Por ejemplo, sí que hacía distinción entre criados y criadas ("Criados, y Criadas") y entre amos y amas ("Las amas, y Amos"), pero no lo haría con adjetivos como malcontentos, rencillosos y aquellos, porque no era necesario pragmáticamente. Por último, cuando tocaba hablar de un solo sexo (de criadas exclusivamente, por ejemplo, cuando se dice "y particularmente en las mugeres"), se utiliza el género marcado para dicho sexo y no la función "no marcada" (neutral) del género:

(3) Reflexion. Las personas de uno, y otro sexo, à quienes Dios, ò la constitucion de su estado ha reducido a servir, padecen un sensible desconsuelo por no saber tan pronto, como lo pide su desacomodo, casas que busquen criadas, ò criados. Esta especie de gentes, sin las que no puede sostenerle el govierno economico de la assistencia, y servicio de las casas, viven con la esperanza de su colocacion, en unos medios nada proporcionados à su buen deseo, pues se encomiendan à pobres del Hospicio, o se entregan al arbitrio de la carnalidad, en cuyos lentos, y perezosos medios padecen ellos, y sus futuros Amos; estos, no teniendo quien los sirva, ò aguantando criadas, ò criados negligentes, malcontentos o rencillosos, hasta encontrar otros mejores, ò menos malos, y aquellos, sufriendo las molestias de dissiparle, y mal vender lo que ganaron para mantenerse todo el tiempo que dura su desacomodo. No es lo mas esto, mayor daño hay, y particularmente en las mugeres. Este es el riesgo à que se exponen las criadas quando se les retarda la conveniencia. Sucede, y es lo mas regular, que el paradero de las criadas, que se desacomodan (si no tienen padres, ò parientes, que las abriguen) es en casa de alguna, que ellas llaman amiga, conocida, o compañera, donde se refugian hasta colocarse, y à veces estas amigas son unas pobres gentes, que no tienen pan que llevar à la boca, y comer algo, sino el tiempo que les dura la desacomodada. La miserable constitucion de la casa en que se hospedan algunas infelices criadas, ocasiona una muchedumbre de males, que se conocen quando no hay remedio o el menor de todos estos, es, ir poco à poco gastando el dinerillo que ahorraron de su salario; tras de este (si dura el desacomodo) venden los vestidos, y se reducen à un estado, que las inspira (este es el mayor dolor!) verguenza, à causa de su desnudez, para ponerse à servir, y ningun miedo para abandonarse à pecar. La causa original de estos deplorables efectos, es la pobreza, ò la malicia de la casa en que se hospedan; pero si huviera havido un DIARIO como el presente, que diera noticia de las mugeres, y hombres desacomo- 
dados, seguro es, que no huvieran sido tan atrevidos los riesgos. No hay menos precipicios para los hombres, que para las mugeres; pues por la misma razon dada, ò à causa de las malas compañias, que les ofrece su ningun oficio, y les precisa a buscar el verse sin acomodo, se arrojan à la rapiña, ò al juego, y quando à esto no, a la limosna, y por dioseo; de tal modo, que si por desgracia toman el mal entendido gusto de qualquiera de estos abandonos, lo menos que sucede, es, hacerse inutiles, y gravosos para el comercio humano.

(pp. 18-19)

En la página 21 del mismo número, se continuaba diciendo que "entregando los niños à mas Amas que ya que no suplan el afectuosisimo amor de sus propias Madres, no inspiren para lo succesivo infestadas costumbres", sin producirse la antineutralización en niños o niñas, porque aquí sí funcionaba el morfema -o como forma "neutral" que cumple con la función no específica (o no marcada) del género. Este hecho vuelve a reflejar cómo querer "desambiguar" el sincretismo de género dado en el llamado "masculino genérico" depende de lo que la conciencia de quien escribe o habla quiera entender y, sobre todo, de la comprensión del contexto, y de ahí la dificultad pragmalingüística de desentrañar cognitivamente cuándo el hablante activa o no la conciencia del sexo a la hora de utilizar el "genérico" ${ }^{20}$. Finalmente, en el Punto Decimo, declaraba: "Todas aquellas personas, ricas, poderosas, ò medianamente acaudaladas, que tuvieren dinero para imponer, pueden sin la costa del cuidado, y sin el rezelo de algun fraude, conseguir sugetos, que necessiten su favor", donde puede percibirse que el autor comprendia que el género del epiceno persona y sus consiguientes adjetivos "ricas, poderosas, ò medianamente acaudaladas" no referian tampoco el sexo de los sujetos que se mencionaban, por lo que no hacía falta distinguirlos ya que ese uso del género gramatical femenino aquí poco - nada- tendría que ver con el sexo de aquellos a los que se nombraban. Esto demuestra por qué en la conciencia de los hablantes de español del siglo XVIII (y así hasta la fecha) había estruc-

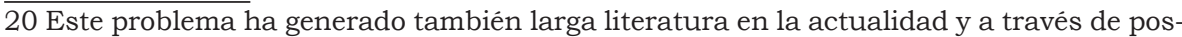
turas muy enfrentadas, para lo que destacamos algunos trabajos como los presentes en Perissinotto (1983), Del Valle (2018), Grijelmo (2019), Escandell-Vidal (2020), por ejemplo. Aunque lo interesante en este trabajo de corte histórico es encontrar el uso implícito que del género no marcado hacian los autores, independientemente de que a veces sí necesitaran acudir al desdoblamiento, lo que también nos ofrece pistas sobre el hecho constatado de la función "neutral" del género en español, que poco o nada tiene que ver con la referencia a lo 'macho', al menos en la conciencia de quien así lo usa en un momento sincrónico y sin activar cognitivamente la otra función (sincretizada en la misma forma) del género marcado ('macho'). En el fondo, se trata de una cuestión parecida (solo que sin la problemática de la identificación del sexo) a la que habría en la conciencia de un hablante a la hora de seleccionar qué significado de una palabra polisémica como banco quiere extraer cuando la usa en un contexto determinado (esto es, si prefiere interpretarlo como "lugar donde sentarse" o como "sucursal bancaria"). Sobre esta activación por la que la lengua española a veces debería ser interpretada como designadora de sexo o no según el contexto y los diferentes sincretismos manifestados tanto en el nivel morfológico como en el nivel léxico-semántico, y para la que es el hablante en última instancia quien decide "interpretarla" de una u otra forma, se han utilizado en anteriores trabajos los postulados de la sociolingüística cognitiva (Moreno Fernández, 2012) para tratar este mismo tema del desdoblamiento en la interacción según la cognición del que así se expresaba (Sancha Vázquez, en prensa). Dado que los estudios de sociolingüística cognitiva tratan de "habla" en sincronía y también de reglas del hablar universal como las máximas del principio de cooperación, estos postulados han servido asimismo para el estudio del desdoblamiento, ya fuese en el presente o en la historia de nuestra lengua. 
turas en la lengua que, independientemente de su género gramatical, no servian para designar un mismo sexo de la realidad extralingüística, lo que en el caso de los epicenos podría describirse como "designación sexual cero" dentro de un universo de conciencia determinado ${ }^{21}$.

Por otro lado, en la página 2 de este primer número, es curioso constatar que, si bien antes en la introducción se explicaban normalmente las profesiones con el desdoblamiento de género, como se ha visto, no resulta así cuando, como portavoz del Diario, el que escribe (Nifo) se dirigía al público en el artículo de lo curioso-erudito: "Muy Señores mios, y à quienes debo ofrecer mi obsequio, y amor con la sencillez mas fina, y menos afectada"; "letargo de algunos Españoles, que podrian ser utiles, y aun gloriosos para el estado". En este tipo de texto no se producen las mismas antineutralizaciones anteriores porque el "prólogo" posiblemente entroncaría con una tradición discursiva diferente que no lo precisaba, ya que aqui no habria "contraste de sexos" que requiriese un recurso oral como el que estamos analizando, el cual sí lo habría en la "tradición discursiva profesional" que pretende agruparse con los testimonios seleccionados. A su vez, el final de esta página se dedicaba completamente a un excurso sobre el famoso debate dieciochesco de la mujer y el espacio público, pues se hablaba de sus "doctos ingenios" y se refería a ellas como "Señoras que se interesan por muy diferentes materias" — consideradas no "mugeriles»- Así, por ejemplo, llamaba "varoniles" a aquellas que se "atreven" con las matemáticas. Sin embargo, al final del discurso se dirigía del siguiente modo al público nuevamente: "Assi es. Pues, Señores, y Dueños de mi mayor respeto, y veneracion", lo que era una fórmula de cortesía en la época. Además, en este tipo de textos donde en algunos anuncios se observaba un desdoblamiento que pareciera ir contra la lógica de la economía del lenguaje, podría surgir también la duda de si estos eran escritos así por los propios demandantes al periódico o si era Nifo quien daba forma a estos. De este modo, por ejemplo, se hablaría de "Niñas, ò Niños quebrados" (4), "Gorriones de Indias, machos y hembras, para criar Canarios, y Canarias" (4), "niñas, ò niños" (5); "Ama de criar algun niño, ò niña" (6):

(4) Doña Agueda de Irulegui, hace saber al Pùblico, tiene gracia especial para curar las Niñas, ò Niños quebrados.

[...] Añade mas, y es, que se halla con Gorriones de Indias, machos, y hembras, para criar Canarios, y Canarias.

(Diario noticioso, curioso-erudito, 08/2/1758, n. 4, p. 4)

(5) En la calle de los Preciados, esquina à la de la Zarza, quarto principal, vive un Maestro, que enseña à danzar à la Francesa con primor, y por corto precio, aunque sea à niñas, ò niños: assimismo, dà lecciones de Violin, y Guitarra, de rasgueado, y punteado, todo por cifra.

$(10 / 2 / 1758$, n. 8, p. 3)

21 Se han trabajado conceptos como "universo sexuado" ("genérico") o "universo no sexuado" ("no genérico") para establecer dichas diferencias en trabajos como los siguientes: Sancha Vázquez (2020a: 138-152; 2020d). 
(6) Andres Garcia, que vive en la calle de la Comadre, casa de la Soledad, solicita su acomodo para Ama de Criar algun niño, ò niña en su propia casa.

$$
\text { (06/04/1758, n. 4, p. 112) }
$$

Esta estrategia no sería usada por Nifo únicamente en este diario, sino que la encontrariamos en otras publicaciones de la época del mismo autor, como en su Diario Estrangero (1763), por lo que se comprobaria que era este un fenómeno discursivo del español permitido como potencialidad del sistema, el cual podría, a su vez, describirse como un rasgo estilístico del periodista, dado que parecía también una técnica a la que este acostumbraba. Esto lo hacia con criados y criadas, pero también con actores o actrices (8), etc., tal vez como los juglares en las plazas medievales cuando necesitaban captar la atención tanto de unos como de otras mediante una captatio benevolentiae (otra vez, hablaríamos por ello de la "oralidad" en el texto):

(7) [...] ò lamentarse de la crueldad de sus amadas, ó amigas, ó abandonarse á al enegenacion de los zelos [...] ¿Puede haver cosa mas enfadosa, que vèr siempre ribales y competidores para oponerse à sus pasiones, criados, y criadas para ayudarles en sus locuras y extravagancias? Siempre una misma cosa!

(Diario Estrangero, 1763, n. 11, p. 170)

(8) [...] que aquellos Actores, ò Actrices mas sobresalientes, y mas favorecidos quando representaban.

(n. 14, p. 219)

Del mismo modo, el desdoblamiento podría describirse como fenómeno bajo otras plumas en tantos otros periódicos de la época. El doblete criados y criadas también podia tener su correspondencia en una palabra más diplomática como discípulo o pupilo ("Â sus discípulos y discípulas" en 9; "Discipulos del uno y del otro sexô" en 10 y "pupilos, de uno y otro sexo y demás personas" en 11). Sobre esta última referencia, es interesante descubrir que se desdobla perifrásticamente los "pupilos, de uno y otro sexo", pero no todos los títulos familiares-profesionales mencionados anteriormente: "los padres de familia, tios, tutores, sus hijos", porque en estos casos no habria una necesidad referencial de distinguir sus sexos. Asimismo, la bimembración se daría en el "contraste de sexos" de enunciados como "cada Gentil hombre, y con cada Dama en particular" de manera perifrástica y sintáctica nuevamente (10):

(9) Leccion I. Á sus discípulos y discipulas [...].

Voy repasando en mi fantasía la calidad de mis futuros ó acaso posibles Lectores, y los separo en dos clases.

(El Filósofo a la moda ó El Maestro Crítico, 1788, n. 1, p. 5) 
(10) Por esto que mira la método de enseñar, yo he tomado el partido de tener de las horas señaladas à la mañana, y al despues de medio dia, à las quales todos mis Discipulos del uno y del otro sexô se asamblarán, para que yo pueda les dár, asi asamblados, mis lecciones, por esto que Vm. vé bien que de trabajar con cada Gentil hombre, y con cada Dama en particular, esto seria una cosa à que yo no hallaria mi cuenta: yo que he determinado de no llevar que tres, ò quatro libras por cada leccion.

(El Censor, 1781, n. 14, p. 214)

(11) [...] los padres de familia, tios, tutores, sus hijos, sobrinos, pupilos, de uno y otro sexo y demás personas.

(n. 152, p. 12)

También en la reflexión (12), extraída del diario El Pensador (17621767), podemos encontrar cómo se desdoblaba el género en criados y criadas, tal y como también hacía Nifo en su Diario, simplemente porque se trataba de una enumeración de diferentes profesiones con las connotaciones asociadas a cada realidad sexual. Esto demostraría la hipótesis de que en aquel momento histórico importaba la diferencia entre un criado y una criada por sus diferentes funciones. Aun así, al final de esta "comedia de enredo" lingüística, se utilizaba la forma "neutral" de las estructuras gramaticales ("criados de enemigos precisos", "como esclavos", etc.), pues los elementos anteriores se suman a un todos "inclusivo" - neutral, con función no específica del géneroen "todos gritan". Asimismo, se observa dicho fenómeno en los testimonios que siguen $(13,14)$, incluso en "Perros y Perras de falda" en (15):

(12) Dá Madama una buelta à su casa con pretexto de vèr si reyna en ella el orden, y el asséo; pero en la realidad solo por hacer un poco de exercicio, y digerir su chocolate: empieza á reñir à criados, y criadas: nada està bien puesto, nada à su gusto. La Criada se ha levantado tarde: el Cochero no ha venido à tomar la orden: el Lacayo se ha dejado una ventana abierta: el Page ha olvidado escribir el papel à una amiga, y el Comprador no ha venido aùn de la Plaza. Hay gritos, juramentos, y maldiciones. La Criada es una insolente: el cochero un borracho; el page un bruto: el Lacayo un salvage; y el Comprador un ladron digno de la horca. Todo se rebuelve: todos gritan; y el diablo parece que anda suelto en la casa. La Señora trata à sus criados de enemigos precisos; y ellos por consequencia forzosa la miran como à enemiga. Diceles palabras injuriosas, y ellos la responden sin decoro. Miralos sin humanidad, y como esclavos, y ellos à su vez la sirven sin respeto, sublevados contra su tyrania.

(El Pensador, 1762, n. 20, p. 194)

(13) Pues ahora entremos con el gasto diario de comida, criados, y criadas, que no para seguramente en mil ducados.

(El Pensador, 1763, n. 53, p. 2) 
(14) [...] por haber mordido en la nariz à su Ama un Perrito de esta especie, al darle besitos en el hozico, habia ella rabiado, no de otra suerte que si la hubiese mordido un mastin: Que sin ser mordidas, rabiaban muy comunmente las personas que los usan por causa de ellos; de manera, que no habia criado, ni criada que las pudiese aguantar, si tal vez los habian tocado á n pelo, si no les daban el chocolate caliente, si no los acariciaban, y besacaban como á niños, y si no los cuidaban como si fuesen sus hijos.

(El Censor, 1781, n. 21, p. 318)

(15) [... todo lo qual cedia en grave oprobio y verguenza, no solo del delinquente, que éste no debia de conocerla, sino tambien de todo el sexo barbado; y para su remedio, como igualmente para el de los demás abusos expuestos, y de los otros que omitian por ser bastantemente notorios; concluian pidiendo, fuesemos servidos de mandar despachar nuestra Censura en forma, para la entera abolicion de los dichos Perros y Perras de falda, como cosa por otra parte à todos respetos, inutilisima; mandando se extinguiesen y descastasen, como està mandado hacer con los urones; todo baxo las comminaciones, y penas censorias que tubiesemos por convenientes.

(El Censor, 1781, n. 21, p. 320)

Otro ejemplo paradigmático podríamos hallarlo en un periódico emblemático de la época, que fue dirigido por Beatriz Cienfuegos, una mujer a la que se la desacreditó por razón de su sexo y en donde se halló esta carta de un hombre a la Pensadora Gaditana (1786), texto en el que se producía una antineutralización debido a la confusión que causaba la labor de su sexo a ojos de la crítica de la época. En este contexto, para diferenciarla del otro "Pensador" (José de Clavijo y Fajardo, por el que había tomado tal nombre), se produciria este desdoblamiento en "ser Pensador, ó Pensadora", lo que jugaba con la ambigüedad que suscitó su propio título de mujer que escribía en la prensa pública:

(16) Pues no fué nada de esto, porque serian felicidades en comparacion de mi desgracia: mas de quatro veces hubiera tomado por partido ser Pensador, ó Pensadora, exponiendome á sufrir sin decir esta boca es mia, las groseras, é ignorantes satiras de la embidia de los ociosos, antes que verme en la triste situacion en que me hallo. Estoy perdido, y aun me he querido pregonar, por ver si me encuentro; pero el imposible de conseguirlo me lo ha borrado de la cabeza.

(La pensadora gaditana, 1786, tomo I, p. 52)

\section{1. ¿EXCLUSIVIDAD DE LA "TRAdICIÓN DISCURSIVA PROFESIONAL" EN LA PRENSA?}

Evidentemente, el desdoblamiento o la bimembración de pares aquí analizado como fenómeno mayormente entre criados y criadas en la prensa del siglo XVIII, así como el que se daba con otros títulos profesionales, podría deberse a diferentes razones y se podría dar en diferentes tipos de textos, como sucede también en el texto jurídico (lo que se puede comprobar de hacer un rastreo en diversos corpus diacrónicos y lo que, además, se ha mencionado apoyándo- 
nos en otros estudios en los antecedentes; \& 1.2.). Por ello, con esta pequeña muestra se deja únicamente constancia de que esta necesidad referencial suele darse también en este tipo de textos dentro de una tradición discursiva que habríamos denominado aquí "profesional". Esta, además, no sería exclusiva de la prensa y podría, por tanto, aparecer en otros géneros textuales donde un texto con este tipo de características podría potenciar el fenómeno pragmático-discursivo en la interacción de los hablantes que así escribían ${ }^{22}$.

Una búsqueda en el corpus diacrónico CORDE con la clave "criados y criadas" entre los siglos XVIII y XIX arrojó 1826 casos en 182 documentos; y otra con "criados o criadas", 3022 casos en 641 documentos, de entre los que destacan muy diferentes géneros textuales, tales como "tratados jurídicos", "documentos notariales", "relato extenso novela", y otros. Evidentemente, si se hace una lectura pormenorizada, no todos son casos de desdoblamientos, pues a veces se hacía mención solo a uno u otro sexo. Sin embargo, si vamos más allá del conjunto de periódicos revisados y analizamos algunos de los casos obtenidos en este otro corpus, se puede encontrar también el desdoblamiento en textos de otra índole, por ejemplo en uno novelesco como La Regenta donde al hablar de los criados también puede leerse: "Aquella señora aya tenía criados y criadas y un señor que venía de noche y le daba besos a doña Camila" (La Regenta, año 1884-1885, edición de Gonzalo Sobejano, Castalia, Madrid, 1990, p. 169). Con esto queremos resaltar simplemente que la denominada aquí "tradición discursiva profesional" no estaría limitada únicamente al tipo de texto de "anuncio" en la prensa, como ya se ha discutido, sino que esta tradición podría abarcar textos de muy diferente índole siempre y cuando estos tuvieran relación con lo "profesional" y, a su vez, surgiera aquella necesidad pragmático-discursiva, dado que el desdoblamiento como fenómeno del texto o el discurso concreto es una herramienta "oral" que podría darse en todo tipo de géneros textuales.

\section{Visión PANORÁmica del FENÓMENo EN LA PRENSA DECIMONóNICA}

Para entender que esta "tradición discursiva profesional" abarcaría el fenómeno en otro tipo de periódicos y a lo largo de una linea del tiempo, se han rescatado algunos testimonios de periódicos del siglo XIX donde se podía observar el mismo fenómeno de bimembración para destacar el sexo, el de ellos y el de ellas. La idea central de este

$\overline{22 \text { Como muestra }}$ de esto, obsérvese el siguiente testimonio, también de la prensa del siglo XVIII, donde se personifica la Plaza Mayor de Madrid en una mujer, quien se dirige a los "Señores Dictadores del Correo de Madrid". En este texto, cuando se hace mención expresa a tales profesiones, también solía darse el desdoblamiento, aunque no siempre. Por ejemplo, sí se desdoblaba en "Veo con injuria mia que lo que subministraba un corto número de criados y criadas que estaban á mi cargo se halla repartido en centenares de personas robustas dignas de estar empleadas en destinos mas utiles para ellos mismos", pero no en "siendo la gravedad de todos ellos tan grande que el que menos tiene tres criados para el despacho de los generos". Asimismo, en el propio texto, a veces se refiere a un género exclusivo cuando la realidad no exigía referencia al sexo por doble partida: "surti mi jurisdiccion de cierto número de criadas para el despacho de los comestibles" (Correo de Madrid [ó de los ciegos], 17/07/1787, n. 78, p. 334). 
epígrafe es resaltar, una vez más, cómo la necesidad de desdoblar el sexo 'macho' y el sexo 'hembra' a través de estructuras gramaticales sucedería según unos condicionamientos determinados en el texto concreto donde se entablaba discusión sobre diversos títulos profesionales (como se ha descrito en $\& 1$. 2.) Por ejemplo, esta situación se repetía también en el siguiente ejemplo de forma perifrástica (17):

(17) $[\ldots]$ para los trabajadores de uno y otro sexo.

(La Época, 4/4/1886, n. 12107, p. 1)

De igual modo, los trabajadores podrian ser "sirvientes de uno y otro sexo" (18), "cantantes de uno y otro sexo" (19), "actores de uno y otro sexo", así como cobrar forma en jóvenes "de uno y otro sexo" (21-22), que en su instrucción se harian "obreros", asimismo, "de uno y otro sexo" (23), etc. Tanto la voz sirvientes como cantantes, actores o jóvenes son de género no marcado (o sea, estructuras neutrales que no designan el sexo). Además, entiéndase que la palabra jóvenes, aunque no es un sustantivo epiceno, parece funcionar como tal al no aparecer determinada (lo que ocurre con muchos sustantivos comunes), ambigüedad que causaría no saber el género, y, por tanto, exigir la antineutralización de dicha voz de alguna manera:

(18) Nueva policia.- - Se quejan algunos caballeros, amos de casa, de la lentitud y groseros modales que emplean algunos sub-comisarios de policia para despechar á los sirvientes de uno y otro sexo que se presentan á proveerse del nuevo padron, en cumplimiento á las órdenes de la autoridad.

(El Clamor público, 12/5/1847, n. 918, p. 3)

(19) $[\ldots]$ y cantantes de uno y otro sexo que pretendian agradar en Sevilla.

(Semanario pintoresco español, 27/11/1853, n. 48, p. 6)

(20) $[\ldots]$ actores de uno y otro sexo que incurrieron en deslices dignos de repobración.

(Revista contemporánea, 9/1883, n. 47 p. 37)

(21) [...] igualar las aspiraciones, deseos y sentimientos de los jóvenes de uno y otro sexo.

(4/1892, n. 86, p. 276$)$

(22) [...] la cual se da toda clase y género de instrucción á jóvenes de uno y otro sexo.

(p. 496)

(23) Compañía, donde trabajan sobre dos mil ochocientos obreros de y uno otro sexo. 
Sobre el tipo de texto de anuncios donde aparecian los criados y las criadas, en (24) encontramos la misma estructura bimembre (sirviente), la cual serviría - valga la redundancia- como sustantivo común, al que no se le cambiaba la terminación, sino que se decidía explicar, por ejemplo, en "sirviente masculino ó femenino", 1o que sería una antineutralización manifestada sobre la naturaleza de este sustantivo no determinado y de manera otra vez sintáctica.

(24) No hay en Madrid, domicilio alguno, donde después de llamar ipor lo menos dos veces no se corra la regula ó abra el ventanillo, para asomar el hocico, más ó menos pulcro, mejor ó peor configurado, un sirviente masculino ó femenino, que empezando por la frase sacramental de ¿quién? no concluya por moler á preguntas tales como ¿quién es usted? ¿cómo se llama Vd.? ¿qué quería Vd. y á quién busca usted? etc., etc., etc.

(El Solfeo, 30/7/1876, n. 296, p. 2)

Este mismo fenómeno explicado con la voz de género común el/la joven o en el/la sirviente se repetiría en el/la artista. Ello explica que en la siguiente revista de mujeres (25), cuando se menciona a "algunos de los llamados artistas", esta voz aparezca dentro de un señalamiento "neutral" — "los llamados artistas"-, y que con la letra cursiva ${ }^{23}$ se adelante un significado especial que iba a antineutralizarse una línea más tarde: "en los cuales están comprendidos los sexos masculinoy femenino", o sea, que hacía falta explicarlo y de ahí la proyección del recurso tipográfico:

(25) Todas las demostraciones de aplauso son justas, si se atiende al mérito de algunos de los llamados artistas, en los cuales están comprendidos los sexos masculino y femenino ${ }^{24}$.

(Album de señoritas y Correo de la moda, 24/7/1859, n. 315. p. 215)

Por último, obsérvese un nuevo testimonio en (26), donde aparecía un uso extraño de la expresión bimembre sintagmática "de ambos sexos", que en este caso particular se utilizaba en referencia a "las empleadas" de Valencia de todos los "empleados en el servicio telegráfico y telefónico de Madrid". En este texto se produce una antineutralización que no se podría entender sino como lo que pudiera ser un error, dado que, en realidad, en tal contexto se debería esperar la forma neutral (no marcada) empleados para que el sintagma sirviese como estructura aclaradora (a menos que se considerara el morfema flexivo - $a$ de empleadas con función no específica — neutral—, lo que no sucede en la lengua española ${ }^{25}$ ):

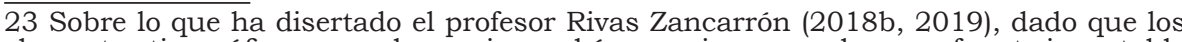
elementos tipográficos como la cursiva podrian servir a menudo como fuente inagotable de actitudes lingüísticas.

24 Este caso, puesto que se trata de un sustantivo de género común, podría haberse resuelto con el desdoblamiento del artículo: "los y las artistas", pero el autor decidió hacerlo contextualmente para señalar explícitamente ambos sexos y, así, de esta manera, desdoblarlos.

25 A pesar de lo que se ha hablado sobre un supuesto "femenino genérico" en el presente (Del Valle, 2018; Âlvarez de Miranda, 2020). 
(26) Como ya hemos defendido, y con fundadas razones, á los empleados en el servicio telegráfico y telefónico de Madrid, hemos de defender á los de Valencia (y allí á las empleadas de ambos sexos), á los que se ha acusado, por medio de La Correspondencia de Espa$\tilde{n} a$, de insuficiencia en el servicio.

La prensa valenciana ha acudido á la defensa de los que han sido injustamente atacados; pero lo que de los repetidos ataques deduce la persona que observa, sin pecar de malicioso, es que lo que se trata es de desprestigiar á los empleados del Estado, para proteger empresas particulares, asi como también de procurar sustituir á las señoritas que honradamente ganan la subsistencia y cumplen bien con sus deberes, por hombres que, en razón á su sexo, pueden ser electores y utilizables á la política.

(La Época, 12/5/1886, n. 12144, p. 3)

\section{Conclusiones}

En definitiva, podría decirse que, dentro de la prensa española, en una tradición discursiva perteneciente al discurso de las profesiones o los cargos sociales - la denominada aquí "TD profesional»—, aparecían con recurrencia palabras y sintagmas utilizados para apelar a los dos sexos del espacio extralingüístico, esto es, lo que nos parece un uso coherente el desdoblamiento de género por unas condiciones que el mismo tipo de texto presente en dicha tradición textual exigia o demandaba. En general, puede deducirse, de todo lo dicho hasta aquí, que ya desde el pasado histórico de nuestra lengua las personas parecen identificar la categoría óntica "sexo" de la realidad con el género gramatical de manera más normalizada al hablar de profesiones, posiblemente por una cuestión de identidad de los sujetos que así son interpelados en el discurso concreto. Por este motivo se producian desdoblamientos, estructuras bimembres y otros recursos contextuales, los cuales también servian, asimismo, para explicar el sexo 'macho' o 'hembra' de los sujetos designados a través de la lengua española, lo que podría declararse una "regla discursiva" para la aquí denominada "tradición discursiva profesional», la cual podría encontrarse en múltiples medios escritos y no únicamente en la prensa. Por esta última razón, pensamos que convendría analizar este fenómeno más allá de las fronteras colindantes en este trabajo, con el objeto de encontrar este mismo recurso discursivo a lo largo de la historia de la lengua española como dispositivo de la conciencia de los hablantes a la hora de desambiguar el sexo debido a necesidades referenciales específicas. Estas necesidades específicas tendrian mucho que ver con la tradición discursiva donde almacenáramos cada texto estudiado; de ahí la hipótesis que se ha mantenido en este trabajo desde el inicio. Dicho esto, dado que aquí se ha descrito este fenómeno en un conjunto de testimonios de la prensa de los siglos XVIII y XIX, sería interesante estudiar estos mismos fenómenos en otros medios, así como en el siglo XX con el propósito de dar continuidad a la hipótesis hasta ahora trazada en esta línea temporal. 
Por otra parte, la mayoría de usos lingüísticos aquí presentados podrían estudiarse gracias a una pragmalingüística histórica que tuviera amparo en el concepto de "tradiciones discursivas" (por ello, "de inspiración coseriana"). Así, el desdoblamiento de género podría describirse, en un primer lugar, como su propia TD y, asimismo, en segundo lugar, como una "regla discursiva" de tradiciones discursivas diversas. En este trabajo lo hemos analizado dentro de la llamada "TD profesional». Por ello, el tipo de texto que se ha encontrado en la prensa de los siglos XVIII y XIX dentro de diferentes géneros textuales, aquel en relación siempre con profesiones y cargos sociales, ha servido para analizar cuándo los autores desdoblaban el género gramatical en relación con los sexos designados. En dichas situaciones este fenómeno podria describirse como una "regla discursiva" de aquel "saber discursivo-tradicional" que cada sujeto poseía a la hora de realizar un discurso cuando le hiciera falta. La bimembración o el desdoblamiento de género correspondia, sobre todo, a anuncios laborales o textos que, en general, versaban sobre cargos de las personas en sociedad, donde periodistas y ciudadanos de a pie precisaban hablar de su realidad, sobre todo en lo concerniente a profesiones, asi como lo harian los editores cuando se dirigian a criados y criadas, actores y actrices, en definitiva, a trabajadores de uno y de otro sexo. Para ello, el hablante contaría, dentro de lo que se ha denominado la "tradición discursiva profesional", con este artilugio discursivo disponible en la lengua española (el desdoblamiento de género), con el que sería capaz de activar la correlación entre el género gramatical y el género biológico en la interacción comunicativa o escrita desde tiempos pretéritos. Dicho así, el hablante seleccionaba y activaba en su conciencia lingüística diferentes formas de referirse a entes sexuados a través de su objeto comunicativo, lo que hacía en última instancia mediante las técnicas de las que dispone la lengua española para dicho fin, las cuales no deberian juzgarse como "válidas" o "inválidas" más que según la justificación que exigiera un discurso determinado.

\section{REFERENCIAS}

\section{(Fuentes PRimarias)}

ALBUM DE SEÑORITAS Y CORREO DE LA MODA (1853-1864). Madrid, El correo de la moda. [Ultimo acceso: 12/09/2018].

ANTOLOGIA ESPAÑOLA, REVISTA DE CIENCIAS, LITERATURA, BELLAS ARTES Y CRITICA DE EL SIGLO, Madrid, Imprenta de El Siglo, 1848. [Último acceso: $10 / 11 / 2017]$.

CORREO DE MADRID (Ó DE LOS CIEGOS) (1786-1791). Madrid, Imprenta Real y de Josef Herrera.
[Último acceso: 15/11/2017]. DIARIO DE LAS MUSAS, Madrid, Impr. Hilario Santos Alonso, 1790-91. [Último acceso: 20/11/2017].

DIARIO ESTRANGERO, NOTICIAS IMPORTANTES Y GUSTOSAS PARA LOS VERDADEROS APASIONADOS DE ARTES Y CIENCIAS, Madrid, Imp. de Gabriel Ramírez, 1763. [Último acceso: 20/11/2017].

EL CENSOR (1781-1787). Madrid. [Ú1timo acceso: 20/08/2018]. 
EL CLAMOR PÚBLICO, PERIÓDICO POLÍTICO, LITERARIO E INDUSTRIAL (1844-1864). Madrid. [Ú1timo acceso: 20/08/2018].

EL FILÓSOFO A LA MODA Ó EL MAESTRO CRÍTICO, Madrid, Anónimo, 1788 . [Último acceso: 12/09/2017].

EL HABLADOR JUICIOSO Y CRÍTICO IMPARCIAL, Madrid, Imprenta de Francisco Xavier Garcia, J. Langlet, 1763. [Último acceso: 12/09/2017].

EL PENSADOR (1762-1767). Madrid, Imprenta de Joachin Ibarra. [Último acceso: 20/08/2018].

EL PUBLICISTA, Madrid, Impr. de D. T. Jordan, 1840. [Último acceso: 12/09/2017].

EL SOLFEO (1875-1878). Madrid, El Solfeo. [Último acceso: 20/08/2018].

LA ÉPOCA (1849-1936). Madrid, La Época. [Último acceso: 20/08/2018].

LA PENSADORA GADITANA (1786). Cádiz, Imprenta de D. Manuel Ximenez Carreño. [Último acceso: $20 / 08 / 2018$.

NOTICIAS LITERARIAS DE ESPAÑA, Madrid, 1763. [Último acceso: 23/11/2017].

REVISTA CONTEMPORÁNEA (18751907). Madrid, Revista contemporánea. [Último acceso: 20/08/2018].

\section{(Fuentes secundarias)}

ALMEIDA CABREJAS, B. (2012): "Masculino inclusivo, masculino no inclusivo $\mathrm{y}$ femenino en la denominación del sujeto de derecho en fueros y documentos", e-Spania, 13, CLEA. https://doi.org/10.3917/ cehm.039.0039.

ALMEIDA CABREJAS, B. (2016): "Referirse a las mujeres en Vicente Ferrer y Teresa de Cartagena: masculino inclusivo y femeni- no", Cahiers d'études hispaniques médiévales, 39, pp. 39-60.

ÁLVAREZ DE MIRANDA, P. (2020): "Un femenino "no marcado"", El País, disponible en línea, 12/11/2020.

BENGOECHEA, M. (2015): "Cuerpos hablados, cuerpos negados y el fascinante devenir del género gramatical", Alcalá de Henares, Bulletin of Hispanic Studies, 92(1), pp. 6 y ss.

BOSQUE, I. (2012): "Sexismo lingüístico y visibilidad de la mujer", Boletín de información lingüistica (BILRAE), RAE.

CASTILLO SÁNCHEZ, S. \& MAYO, S. (2019): "El lenguaje inclusivo como "norma" de empatía e identidad: reflexiones entre docentes y futures profesores", $\mathrm{Li}$ teratura lingüística, n. 40.

CANO AGUILAR, R. (1998): "Presencia de lo oral en lo escrito: la transcripción de las declaraciones en documentos indianos del siglo XVI", Competencia escrita, tradiciones discursivas y variedades lingüisticas: aspectos del español europeo y americano en los siglos XVI y XVII (W, Oesterreicher, E, Stoll y A, Wesch, eds.), Gunter Narr Verlag, pp. 219-242.

COSERIU, E. (1969): Einführung in die strukturelle Linguistik, Tübingen: Romanisches Seminar.

COSERIU, E. (1992): Competencia lingüistica: elementos de la teoría del hablar, Madrid: Gredos.

DEL VALLE, J. (2018): "La política de la incomodidad", Anuario de Glotopolitica, disponible en línea, 21/8/2018. <https://glotopolitica.com/2018/08/21/la-politica-de-la-incomodidad/> [revisado 20/04/2021].

ENCISO RECIO, L. M. (1956): Nipho y el periodismo español del siglo XVIII, Valladolid, Universidad de Valladolid. 
ESCANDELL-VIDAL，V. (2018): "Reflexiones sobre el género como categoría gramatical. Cambio ecológico y tipología lingüística", en M. Ninova (ed.): De la lingüistica a la semiótica: trayectorias y horizontes del estudio de la comunicación, Sofia, Universidad S. Clemente de Ojrid.

ESCANDELL-VIDAL， V. (2020): "En torno al género inclusivo", IgualdadES, 2.

FERNANDO LARA, L. (2004): Lengua histórica y normatividad, México, El colegio de México.

GRIJELMO, Á. (2019): Propuesta de acuerdo sobre el lenguaje inclusivo, Barcelona, Taurus.

KABATEK, J. (2000): "L'oral et l'écrit -quelques aspects théoriques d'un "nouveau" paradigme dans le canon de la linguistique romane", en Wolfgang Dahmen et al. (eds.), Kanonbildung in der Romanistik und in den Nachbardisziplinen, Tubinga, Narr, pp. 305-320.

KABATEK, J. (ed.) (2008): Sintaxis histórica del español y cambio lingüístico: Nuevas perspectivas desde las Tradiciones Discursivas, Madrid, Iberoamericana Vervuert, pp. 53-88.

KABATEK, J. (2018): Lingüística coseriana, lingüistica histórica, tradiciones discursivas, Madrid, Iberoamericana, 72 .

$\mathrm{KOCH}, \mathrm{P}$. (2008): "Tradiciones discursivas y cambio lingüístico: el ejemplo del tratamiento vuestra merced en español", en Johannes Kabatek (ed.): Sintaxis histórica del español y cambio lingüistico: Nuevas perspectivas desde las Tradiciones Discursivas, Madrid, Iberoamericana Vervuert, pp. 53-88.

$\mathrm{KOCH}$, P. \& OESTERREICHER, W. (2001): "Langage parlé et language écrit", en Holtus et al. (1988-2005): Lexikon der Ro- manistischen Linguistik. 8 vols, Tübingen, Niemeyer, I/2, pp. 584-627.

$\mathrm{KOCH}$, P. \& OESTERREICHER, W. (2007): Lengua hablada en la Romania: español, francés, italiano, Madrid, Gredos.

LOBO PUGA, A., MARTÍN AIZPURU, L. \& R. SÁNCHEZ ROMO (2015): "De los ricos omnes e de las ricas fembras. Desdoblamientos de género en docuentación jurídica medieval”, en Sánchez Méndez, J. P., De la Torre, M. y V. Codita (2015): Temas, problemas y métodos para la edición y el estudio de documentos hispánicos antiguos, pp. 823-848.

LÓPEZ SERENA, A. (2021): "La tradicionalidad discursiva como materia y las tradiciones discursivas como objeto de estudio", Verba, pp. 1-33.

LOUREDA LAMAS, O. (ed.) (2006): Lenguaje y discurso, Pamplona, Universidad de Navarra: EUNSA.

LLAMAS SÁIZ, C. (2015): “Academia y hablantes frente al sexismo lingüístico: ideologías lingüísticas en la prensa española", Circula: Revue d'idéologies linguistiques, 1, pp. 196-215.

LLEDÓ I CUNILL, E. (2012): Cambio lingüistico y prensa, Barcelona, Laertes.

MORENO FERNÁNDEZ, F. (2012): Sociolingüistica cognitiva, Madrid, Iberoamericana/Vervuert.

PERISSINOTTO, G. (1983): "Spanish hombre Generic or Specific?", Hispania, 66, pp. 581-586.

REAL ACADEMIA ESPAÑOLA: Banco de datos Corpus diacrónico del espanol (CORDE) [en línea] <http:// www.rae.es>. [10/07/2020].

RIVAS ZANCARRÓN, M. (2018a): "Algunas consideraciones sobre las diferencias entre género natural y gramatical. Motivación social vs. motivación lingüística”, en Gaviño Rodríguez, V. y 
Marchena Domínguez, J., Civilización, literatura y lengua españolas, Cádiz, Editorial UCA, pp. 225-238.

RIVAS ZANCARRÓN, M. (2018b): "La forma de los tipos gráficos como instrumento de expresión para las actitudes lingüísticas en la prensa costarricense del siglo XIX", Boletín de Filología, 1, 237-275.

RIVAS ZANCARRÓN, M. (2019): “Actitudes explícitas ante el resalte gráfico en la tradición discursiva periodística española de los siglos XVIII y XIX", Anuario de Letras, vol. VII, pp. 235-271. <DOI: 10.19130/iifl. adel.7.1.2019.1534>.

ROCA, I. (2005a): "La gramática y la biología en el género del español ( $1^{a}$ parte)", Revista de la Sociedad Española de Lingüística, año 35 (1), pp. 17-44.

ROCA, I. (2005b): "La gramática y la biología en el género del español (2 $2^{\mathrm{a}}$ parte)", Revista de la Sociedad Española de Lingüística, año 35(2), pp. 397-432.

ROCA, I. (2009): "Todas las vascas son vascos, y muchos vascos también vascas", Boletín de la Real Academia Española, 89, 299, pp. 77-117.

ROCA, I. (2012): "Algunas reflexiones críticas sobre "Acerca de la discriminación de la mujer y de los lingüistas en la sociedad"”, disponible en "http:// stel.ub.edu/linguistica-ub/webfm_send/55" [20 de marzo de 2014].

SANCHA VÁZQUEZ, J. (2019): Conciencia lingüistica ante la dimensión "género" en el español de la opinión pública de los siglos XVIII y XIX, tesis inédita, Cádiz, Universidad de Cádiz.

SANCHA VÁZQUEZ, J. (2020a): La injerencia del sexo en el lenguaje. Dos siglos de historia del género gramatical en español, Berlin, Peter Lang.

SANCHA VÁZQUEZ, J. (2020b): "La lucha por el poder entre las ideologías "alternativas" y la ideología "hegemónica" del género gramatical en español: reflexiones en torno a la innovación lingüística y la "artificialidad"”, Études romanes de Brno, vol. 41, pp. 249-270.

SANCHA VÁZQUEZ, J. (2020c): “JJe la suis aussi". De pronombre acusado a pronombre acusativo: historia de una antineutralización sociolingüística", en Rivas Zancarrón, M. y V. Gaviño (eds.), Creencias y actitudes ante la lengua en España y América (siglos XVIII y XIX), Iberoamericana Vervuert, $\mathrm{pp}$. 227-250.

SANCHA VÁZQUEZ, J. (2020d): “Exploración de los universos sociolingüísticos "genérico" (sexuado) y "no genérico" (no sexuado) como explicación de la injerencia del sexo en la lengua española: cómo, cuándo y por qué", en Alonso, Borja; Escudero, Francisco; Villanueva, Carlos; Quijada, Carmen y Gómez, José J. (eds.) (en prensa): Lazos entre lingüística e ideología desde un enfoque historiográfico (ss. XVI-XX), Salamanca, Ediciones Universidad de Salamanca.

SANCHA VÁZQUEZ, J. (en prensa): "Niños y niñas en la conciencia lingüística decimonónica. Un caso de activación del universo sociolingüístico genérico en la tradición discursiva escolar", Onomázein, n. 61, <DOI 10.7764/onomazein.61.03>.

SCHROTT, A. (2017): "Las tradiciones discursivas, la pragmalingüística y la lingüística del discurso", Revista de la Academia Nacional de Letras, 13, pp. 25-57. 